Research Article

\section{Production and characterization of staphylokinase enzyme from Staphylococcus aureus ASIA4}

\author{
Nourah Hassan Alzahrani ${ }^{1}$ and Fareed Shawky \\ El-Shenawy2* \\ ${ }^{1}$ Department of Biology, College of Science, University of Jeddah, Jeddah, Saudi Arabia \\ ${ }^{2}$ Botany and Microbiology Department, Faculty of Science, Al-Azhar University, Assuit, Egypt
}

\begin{abstract}
Six clinical Staphylococcus aureus strains isolated from different clinical samples. Isolates ASIA1 and ASIA2 isolated from urine samples of urinary tract infected patients; ASIA3 isolated from swab samples of burn abscess patients at Assiut University hospital as well as ASIA4, ASIA5 and ASIA6 obtained from blood samples of different cancer patients at South Egypt Cancer Institute. All isolates showed varied abilities to produce halo zones of hydrolysis with different diameters on blood agar, heated plasma agar, casein agar and skim milk agar plates along with different clot lyses percent. Staphylococcus aureus ASIA3, ASIA4 and ASIA6 produced $4.83,5.98$ and $2.08 \mathrm{U} / \mathrm{mL}$ of staphylokinase on tryptone soy broth reduced to 1.95 , 2.08 and $1.70 \mathrm{U} / \mathrm{mL}$ on casein hydrolysate yeast extract broth, respectively. On the other hand, Staphylococcus aureus ASIA1, ASIA2 and ASIA5 gave 2.20, 2.93 and $3.65 \mathrm{U} / \mathrm{mL}$ on CYEB compared to $2.10,1.88$ and $3.41 \mathrm{U} / \mathrm{mL}$ on TSB as production medium. The staphylokinase yielded from the hyperactive producer Staphylococcus aureus ASIA4 was increased for 7.64fold (from $2.08 \mathrm{U} / \mathrm{mL}$ to $15.88 \mathrm{U} / \mathrm{mL}$ ) on the optimized fermentation medium composed of 5.0 $\mathrm{g}$ sucrose as carbon source, $10.0 \mathrm{~g}$ soy bean as nitrogen source, $5.0 \mathrm{~g} \mathrm{NaCl}, \mathrm{K}_{2} \mathrm{HPO}_{4} 5.0$ $\mathrm{g}$ and $\mathrm{pH} 7.0$ that inoculated with isolate ASIA4 and incubated for $24 \mathrm{~h}$ at $35{ }^{\circ} \mathrm{C}$. Moreover, Staphylokinase activity reached its peak at the optimal enzymatic reaction conditions which were reaction time $25 \mathrm{~min}$, casein as substrate, reaction $\mathrm{pH} 8.0$, reaction temperature $40^{\circ} \mathrm{C}$. In addition it retained $100 \%$ of its activity at temperature ranged between 15 and $45{ }^{\circ} \mathrm{C}$ and $\mathrm{pH}$ ranged from $\mathrm{pH} 6.0$ to 9.0 . EDTA inhibited the enzyme activity by $3.0 \%$ to $32.2 \%$ with increasing its values from 30.0 to $90.0 \mathrm{mM}$. $\mathrm{MgCl}_{2}$ at a concentration of $30 \mathrm{mM}$ increased the enzyme activity by $4 \%$ and then slightly decreased at higher concentrations but $\mathrm{NaCl}$ was potent staphylokinase activator at concentrations lower than $90 \mathrm{mM}$.
\end{abstract}

\author{
More Information \\ *Address for Correspondence: Fareed Shawky \\ El-Shenawy, Botany and Microbiology Depart- \\ ment, Faculty of Science, Al-Azhar University, \\ Assuit, Egypt, Tel: 00201099654694 ; \\ Email: fareedsh73@yahoo.com \\ Submitted: 29 August 2020 \\ Approved: 16 September 2020 \\ Published: 17 September 2020 \\ How to cite this article: Alzahrani $\mathrm{NH}$ \\ El-Shenawy FS. Production and characterization \\ of staphylokinase enzyme from Staphylococcus \\ aureus ASIA4. Arch Pharm Pharma Sci. 2020; 4: \\ 027-035.
}

DOI: 10.29328/journal.apps. 1001024

Copyright: () 2020 Alzahrani NH, et al. This is an open access article distributed under the Creative Commons Attribution License, which permits unrestricted use, distribution, and reproduction in any medium, provided the original work is properly cited.

Keywords: Staphylokinase; Staphylococcus aureus; Thrombolytic agents; Optimization; Characterization

Check for updates

OPEN ACCESS

\section{Introduction}

Thrombotic disorders are a major cause of death and morbidity worldwide. Thrombolysis like vascular blockage, pulmonary embolism, peripheral occlusive disease, deep vein thrombolysis, stroke and acute myocardial infraction are commonly known as heart attack due to blood clot [1]. Currently, many blood clot-dissolving agents are either approved for clinical use or under clinical examination in patients with acute myocardial infarction, such as staphylokinase, streptokinase, urokinase, tissue plasminogen activator ( $\mathrm{t}-\mathrm{PA}$ ) and plasminogen activator recombinant (rscu-PA; recombinant prourokinase) [2]. There is a lot of research available that includes screen and characterization of microorganisms that produce enzymes with high thrombolysis activity since most of the commonly used medicines have complications such as bleeding, allergies, expensive, re-blockage [3]. Hence, thrombolytic therapy needs additional effective thrombolytic drugs, which afford fast improved efficacy and fibrin specificity of fibrindissolving agents with minimal side effects like minimal bleeding risk and re-occlusion at low cost [4].

Bacterial staphylokinase (E.C 3.4.99.22) is an extra cellular protein composed of 136 amino acids synthesized through the late exponential growth phase of lysogenic Staphylococcus aureus [5]. It has ideal fibrin specific plasminogen activator and clot specificity than t-PA by converting a precursor plasminogen to plasmin which results in dissolving a blood clot along with destroying the natural components of the blood clotting system, leading to life-threatening as well as death consequence [6]. After activation, plasmin cleaves 
variable substrates such as fibrin and extracellular matrix proteins and activates proteases and other growth factors then fibrinolysis including staphylokinase and plasmin are implicated in a variety of physiological and pathophysiological procedures for example wound curing, irritation, cell migration, embryogenesis, cancer development, metastasis, angiogenesis and atherosclerosis [3,7].

The main reason for selecting staphylokinase enzyme in the present study is finding relatively inexpensive thrombolytic drug and alternative cure against cardiac blood clot when compared to other commercial thrombolytic agents. Therefore, the present study has been undertaken to isolate the local strains of $S$. aureus from clinical samples, screened them for the production of staphylokinase (SAK), testing their thrombolytic activity in vitro, optimization the fermentation process parameters and enzymatic assay conditions as well as characterization of the obtained enzyme.

\section{Materials and methods}

\section{Media and reagents}

Nutrient agar (g/L; peptone 5.0, sodium chloride 5.0, beef extract 3.0 and agar 20.0); mannitol salt agar (MSA g/L; peptone10.0, beef extract 1.0, sodium chloride 75.0, mannitol 10.0, phenol red 0.025 , agar 20.0 and $\mathrm{pH} 7.4 \pm 0.2$ ); tryptone broth (g/L; tryptone 10.0, beef extract 3.0, glucose 5.0, blood $5 \%$ and $\mathrm{pH} 7.2 \pm 0.2$ ); methyl red-voges proskauer broth (MR-VP, g/L; tryptone 10.0, glucose 5.0, $\mathrm{K}_{2} \mathrm{HPO}_{4} 5.0$, and $\mathrm{pH}$ $6.9 \pm 0.2$ ), tryptone soya broth (TSB, g/L; pancreatic digest of casein 17,0 , soya bean 3.0 , glucose $2.5, \mathrm{NaCl} 5.0, \mathrm{~K}_{2} \mathrm{HPO}_{4}$ 2.5 and pH $7.3 \pm 0.2$ ) and casein yeast extract broth (CAYE, $\mathrm{g} / \mathrm{L}$; casein acid hydrolysate 30.0 , yeast extract 4.0 , dextrose 2.0, $\mathrm{K}_{2} \mathrm{HPO}_{4} 0.50$ and $\mathrm{pH} 7.2 \pm 0.2$ ) media were used. Methyl red reagent $(0.1 \mathrm{~g}$ MR in $300 \mathrm{~mL} 95 \%$ ethanol and $200 \mathrm{~mL}$ $\mathrm{H}_{2} \mathrm{O}$ ), Voges-proskauer reagent (Barrit B $40 \%$ of potassium hydroxide and Barrit A 5\% $\alpha$-naphthol in absolute ethanol), trichloroacetic acid $\left(10 \mathrm{~g}\right.$ TCA in $100 \mathrm{~mL} \mathrm{H}_{2} \mathrm{O}$ and casein solution (500 mg casein in $100 \mathrm{~mL}$ of $0.1 \mathrm{M}$ phosphate buffer) were prepared.

\section{Collection of clinical samples}

Staphylococcus aureus strains were isolated from different clinical samples from urine samples of urinary tract infected and swab samples of burn abscess patients at Assiut University hospital as well as from the blood samples of different multiple myeloma patients at South Egypt Cancer Institute.

\section{Bacterial isolation and sub-culturing}

All samples were primarily inoculated into nutrient broth, incubated at $37^{\circ} \mathrm{C}$ for $24 \mathrm{~h}$ and serial dilution for each sample were carried out after incubation, $100 \mu \mathrm{L}$ from the appropriate dilution was spread on nutrient agar, mannitol salt agar and blood agar media, incubated at $37^{\circ} \mathrm{C}$ for $24 \mathrm{~h}$ and select expected S. aureus according to Lemaire [8]. The individual colonies were observed, checked for their purity by microscopy. Isolates were maintained on nutrient agar supplemented with $5 \%$ blood at $4{ }^{\circ} \mathrm{C}$ until optimization and characterization studies.

\section{Phenotypic identification of isolates}

Isolates were characterized by following Atlas, et al., Collee, et al., Harlly and Prescott and Kateete, et al. [9-12]. Phenotypic characters including Gram stain, motility, and haemolytic activity. Moreover, antibiotics resistant, catalase (to examine the ability of strains to detoxify hydrogen peroxide via secretion of catalase enzyme which act on conversion of $\mathrm{H}_{2} \mathrm{O}_{2}$ to $\mathrm{H}_{2} \mathrm{O}$ and $\mathrm{O}_{2}$ by adding 2 drops of $\mathrm{H}_{2} \mathrm{O}_{2}$ on a touch of organism colony), carbohydrate fermentation, coagulase ( 0.5 $\mathrm{mL}$ of plasma mixed with $0.5 \mathrm{~mL}$ of broth culture from tested organism), indole (by inoculating tryptone broth medium with tested organisms, incubated at $37^{\circ} \mathrm{C}$ for $48 \mathrm{~h}$ and then Kovac's reagent was added to the test tube and positive result appeared as red layer at the top of medium) and methyl red tests (MRVP by inoculating MR-VP broth medium with each tested isolate, incubated at $37^{\circ} \mathrm{C}$ for $48 \mathrm{~h}$ and then adding MR reagent to test tube and positive result appear as red layer on the top of medium). Identification of isolates was confirmed by VITECK-2 tests.

\section{Screening of staphylokinase producers}

Bacteria are main sources for thrombolytic drugs. Therefore in the current work searching for staphylokinase was performed on the six S. aureus isolates by using different methods heated plasma agar assay, radial caseinolytic assay (including casein agar and skim milk agar assays) and invitro clot lyses at different concentrations $(10,20$ and $30 \mu \mathrm{L})$ of enzyme preparation. After inoculation of SAK producing $S$. aureus on heated plasma agar plate, each clear fibrinolytic halo after each treatment was observed around the well after overnight incubation at $37^{\circ} \mathrm{C}$. In casein hydrolysis assay, the hydrolysis of casein was identified by a zone of clearance around the growth of colonies on casein agar plates and skim milk agar plates after incubation at $37{ }^{\circ} \mathrm{C}$ for $24 \mathrm{~h}$. In vitro thrombolysis study was assayed according to the formula: \% clot lyses $=($ Weight of the lysis clot $/$ Weight of clot before lysis) $\times 100$ at $37^{\circ} \mathrm{C}$ after 90 min of incubating clots with enzyme preparations as previously reported [13-16].

\section{Production and quantitative assay of staphylokinase}

Staphylokinase productivity by a selected $S$. aureus strains was evaluated using two different media namely modified tryptone soy broth (TSB) and casein hydrolysate yeast extract (CYE) at pH 7.0 and $37{ }^{\circ} \mathrm{C}$ for 24 hour at $120 \mathrm{rpm}$. After fermentation period, the activity of staphylokinase $(\mathrm{U} / \mathrm{mL}$ was determined by using casein digestion method [17]. One unit of caseinolytic activity was determined as the amount of enzyme releasing $1 \mu$ mole of tyrosine equivalent/in. 


\section{Optimization of the nutritional requirements and culture conditions for staphylokinase enzyme production by using one factor at a time method}

With the aim of studying the outcome of $\mathrm{pH}$ on staphylokinase production, the fermentation process was performed at various pHs ranged from 4.0 to 9.0 as well as the impact of different incubation temperatures $\left(25\right.$ to $\left.40^{\circ} \mathrm{C}\right)$ on enzyme productivity was assessed. For optimizing nutritional requirements that supported the highest staphylokinase yields, the carbon source in the TSB medium, glucose, was replaced by various six carbon sources including fructose, sucrose, maltose, sorbitol, lactose and starch individually at $5 \mathrm{~g} / \mathrm{L}$. The nitrogen source of TSB (mixture of $17 \mathrm{~g}$ pancreatic digest of casein and $3 \mathrm{~g}$ soya bean) was substituted with peptone, soya bean, casein, beef extract, yeast extract, corn steep liquor and $\mathrm{NH}_{4} \mathrm{NO}_{3}$ individually as sole nitrogen source at $10 \mathrm{~g} / \mathrm{L}$. Effect of the amino acids supplementations (alanine glycine, histidine, cysteine and lysine at a concentration of $2 \mathrm{~g} / \mathrm{L}$ ) in addition to soya bean was assessed. $\mathrm{NaCl}$ of TSB medium was replaced by $\mathrm{CaCl}_{2}, \mathrm{MgCl}_{2}, \mathrm{FeSO}_{4}, \mathrm{KNO}_{3}, \mathrm{ZnSO}_{4}$ and $\mathrm{CuSO}_{4}$ to evaluate the influence of these metal sources individually on the production process of staphylokinase. All the experiments were carried out in duplicates.

\section{Characterization of staphylokinase}

This step was performed in order to maintain the maximum enzymatic activity through optimization of reaction time of assay (at 5 to $30 \mathrm{~min}$ ), $\mathrm{pH}$ of assay and $\mathrm{pH}$ stability of enzyme (at different pH 5.0, 6.0, 7.0, 8.0 and 9.0), impact of temperature on activity and stability of enzyme (at 15 to $60{ }^{\circ} \mathrm{C}$ ), substrate concentrations ( at 0.45 to $3.6 \mathrm{mM}$ ) and the impact of different metal sources $\mathrm{MgCl}_{2}$ and $\mathrm{NaCl}$ as well as EDTA at a concentrations of 10, 30, 50, 70 and 90 $\mathrm{mM}$, individually on enzyme activity were estimated. Growth characterization of $S$. aureus was estimated according to Medved'ová, et al. and Sutherland, et al. [18,19].

\section{Results and discussion}

Isolation, morphological and biochemical characterization of $S$. aureus

Six of $S$. aureus strains were isolated, S. aureus ASIA1 and S. aureus ASIA2 were obtained from urine samples of urinary tract infected patients and $S$. aureus ASIA3 was isolated from swab samples of burn abscess patients at Assiut University hospital but $S$. aureus ASIA4, S. aureus ASIA5 and S. aureus ASIA6 were isolated from blood samples of different cancer patientsatSouth EgyptCancer Institute. Inline with our results different authors reported the distribution of S. aureus in the clinical human samples. For instant Singh, et al., reported that from urine samples of UTI suspected patients screened 119 isolates (33.52\%) showed growth out of which S. aureus were 22 isolates (48.88\%), in which 8 strains were MRSA (36.36\%) and 14 strains MSSA (63.63\%) [20]. Abdulzahra, et al. stated the prevalence of $S$. aureus from urinary tract infection (UTIs) and gastroenteritis patients aged from 8 to 18 years [21]. On the other hand, El-Gendy, et al. reported that cancer patients are susceptible to staphylococcal infection owing to a number of reasons comprising prolonged hospitalization and operating time, intravascular catheterization, compromise immunity, malignancy, chemotherapy, radiotherapy and antibiotic therapy [22,23]. Moreover, El-Gendy, et al. isolated $468 \mathrm{~S}$. aureus isolates from cancer patients among them 283 were MRSA and El-Gendy, et al. isolated 41 clinical $S$. aureus out of them $73.2 \%$ were from El-Demerdash hospital and $26.8 \%$ from Ain Shams Specialized hospital [23,24].

All isolates were Gram positive cocci in clusters or single (Figure 1), in mannitol salt agar medium all S. aureus isolates appeared round, smooth, raised, mucoid, glistening and golden yellow surrounded with large yellow zone due to fermentation of mannitol and production of acid (Figure 2). The isolates were grown on blood agar medium with large, round, creamy grayish white colonies with smooth translucent area surrounding the colonies as a result of $\beta$-haemolysin production (Figure 3). All isolates were positive for coagulase test (coagulase positive Staphylococci, (Figure 4) but negative for indole test (Figure 5). They were catalase and methyl red tests positive (Figure 6). In accordance with our data, previously studies reported that $S$. aureus isolates grown on blood agar with $\beta$-hemolysis activity and on mannitol salt agar medium, which considered a selective and differential medium for $S$. aureus turned its color from red to yellow as a result of mannitol fermentation and acid production and they are positive for catalase, coagulase and MR-VP tests but negative for indole test [5,23-25]. Also, Shah and Panchal, stated that $S$. aureus isolates are snowy, creamy to gold color and as Gram positive cocci with $\beta$-haemolysis on blood agar and proteolysis on casein agar plates [3].
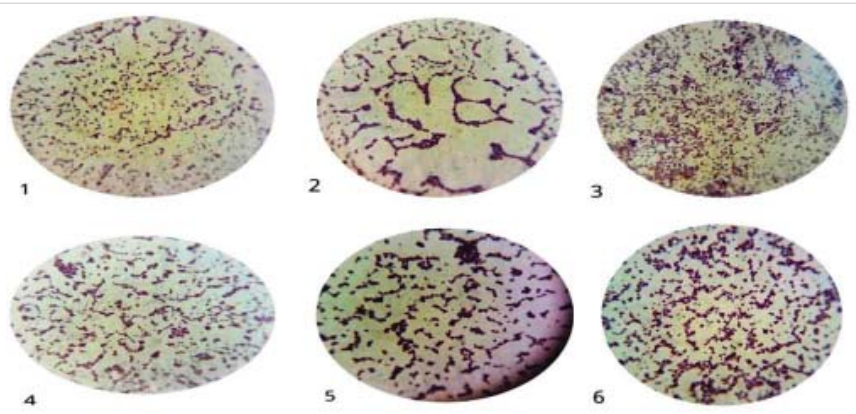

Figure 1: Gram positive cocci of S. aureus ASIA1 to ASIA6 isolates.
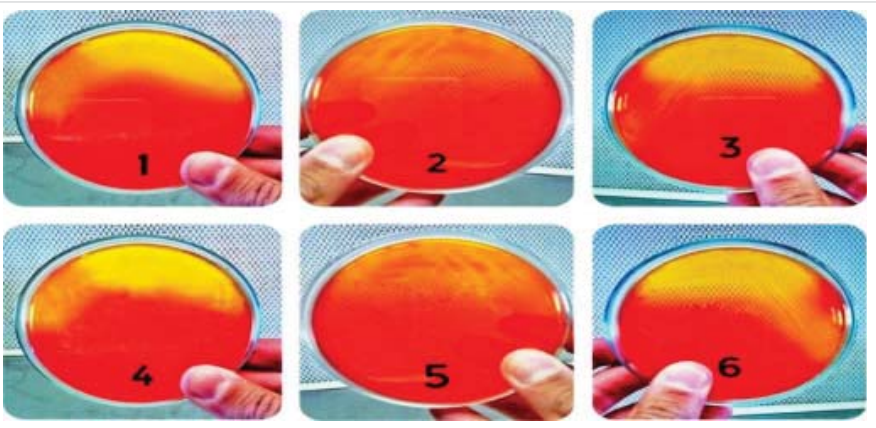

Figure 2: Growth of S. aureus ASIA1 to ASIA6 isolates on mannitol salt agar. 


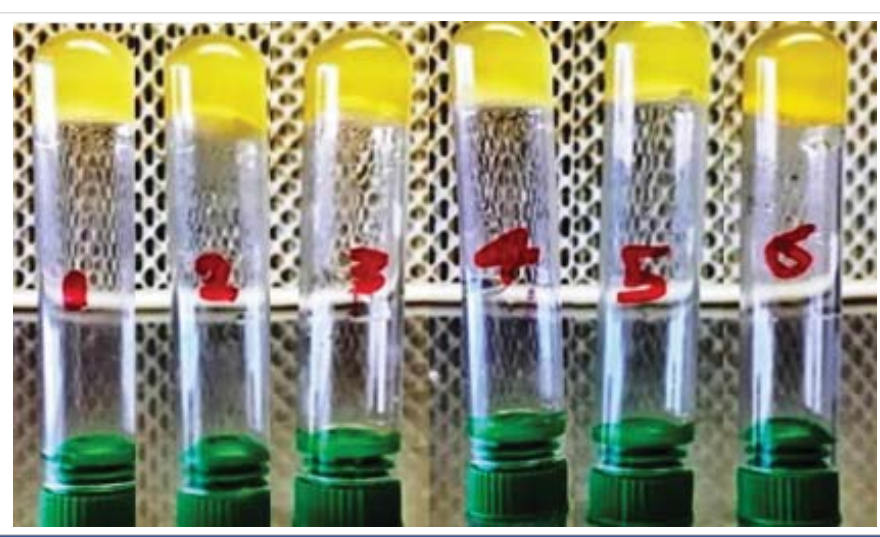

Figure 3: Coagulase positive test of S. aureus ASIA1 to ASIA6 isolates (+ve (clotting).
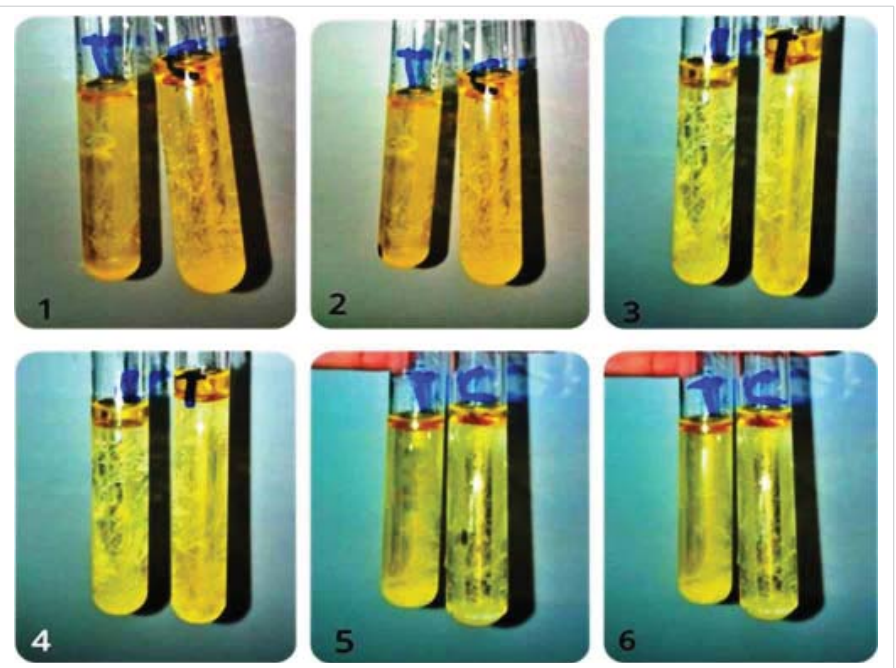

Figure 4: Indole test negative response of $\mathrm{S}$. aureus ASIA1 to ASIA6 isolates, $\mathrm{C}=$ control and $\mathrm{T}=$ treatment.
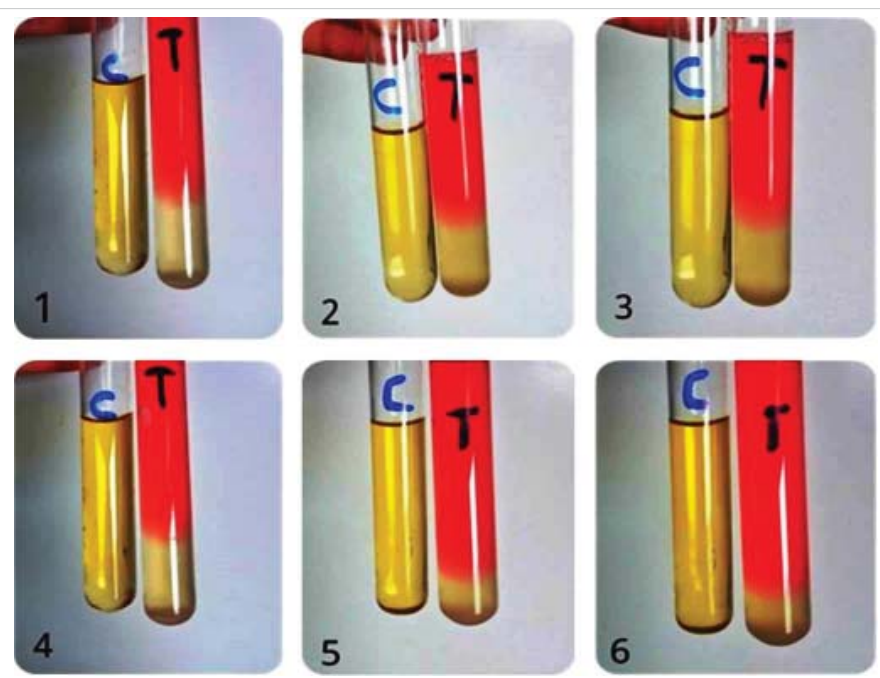

Figure 5: MR-VP positive test of $S$. aureus ASIA1 to ASIA6 isolates, C = Control and $\mathrm{T}=$ Treatment.

Screening of clinical S. aureus strains for staphylokinase activity using different methods

Different methods including hemolysis on blood agar (blood hemolysis activity), heated plasma agar (Plasmolytic activity), casein agar and skim milk agar plates (casienolytic activity) along with determining thrombolysis activity
(\% of clot lysis) were performed to evaluate staphylokinase activity in six isolates of $S$. aureus at different concentrations 10, 20 and $30 \mu \mathrm{L}$. Results in table 1 revealed that all of the six strains showed promising ability to produce hydrolysis halo zones and clot lysis on blood agar, plasma agar, casein agar and skim milk agar plates around each culture filtrate of each bacterial isolate at each concentration. Results also showed that these local isolates differ in their abilities in staphylokinase production. The highest diameter of halo zones estimated to be $(1.80,2.20$ and $2.60 \mathrm{~cm}),(2.0,2.8$ and $3.6 \mathrm{~cm}),(1.3,1.80$ and $2.5 \mathrm{~cm})$ and $(0.8,1.5$ and $2.0 \mathrm{~cm})$ were detected in S. aureus ASIA4 with blood agar, heated plasma agar, casein agar and skim milk agar plates at an enzyme concentrations of 10, 20 and $30 \mu \mathrm{L}$, respectively. Moreover, In vitro thrombolysis study in table 1 showed that the SAK producing $S$. aureus ASIA4 isolate showed the highest present $30 \%, 69 \%$ and $86 \%$ clot lyses followed by S. aureus ASIA3 (24\%, 51\% and 74\% clot lyses) and S. aureus ASIA5 (19\%, $40 \%$ and $67 \%$ clot lyses) after treatment with 10, 20 and $30 \mu \mathrm{L}$ of each enzyme preparation, respectively. Our results are in agreement with Chandrappa, et al. they reported that $10 \mu \mathrm{L}$ of the staphylokinase enzyme can partially lyse the clot, but in between 40 to $60 \mu \mathrm{L}$ complete lysis of the clot was observed [7]. Thrombolytic agents, staphylokinase, can positively impact the outcome of these deadly diseases such as myocardial infarction, cerebrovascular thrombosis, and venous thromboembolism but thrombolysis has major deficiencies including high healing dosages, inadequate fibrin specificity and bleeding problems [6]. Our results are in consonance with other studied achieved by Devriese and Kerckhovea, Pulicherla, et al. and Shagufta, et al. they detected staphylokinase production by $S$. aureus isolated from human infections based on the clear zones of hydrolysis on plasma agar medium after an overnight incubation at $37{ }^{\circ} \mathrm{C}[13,15,16]$. Moreover, Jasim, et al. recorded zones of hydrolysis around the well containing culture filtrate of 19 urinary tract infected $S$. aureus isolates; ranged between 25 and $36 \mathrm{~mm}$ [5], Nedaeinia, et al. stated the ability of $S$. aureus isolates to produce different levels of staphylokinase and producing zone of hydrolysis on plasma agar [2] and Deepa, et al. reported that out of $50 \mathrm{~S}$. aureus isolates, 10 isolates

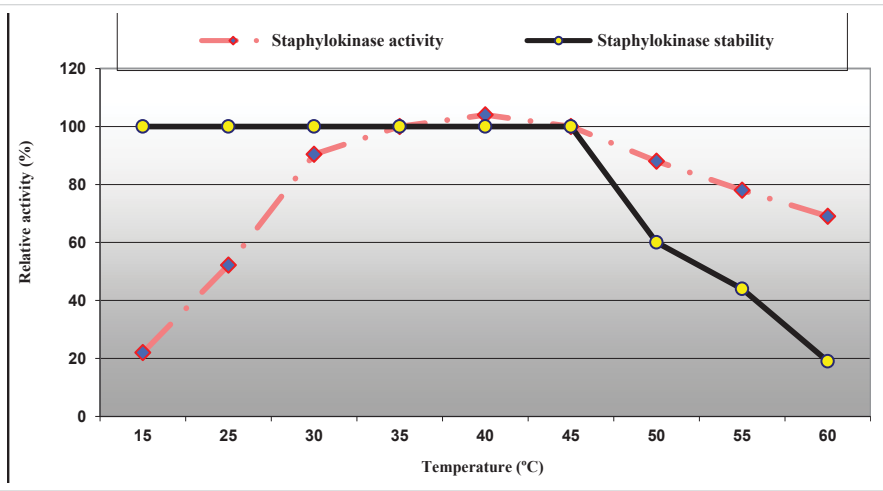

Figure 6: Effect of temperature on staphylokinase activity and stability from S. aureus ASIA4. 


\begin{tabular}{|c|c|c|c|c|c|c|}
\hline \multirow{3}{*}{ Isolate } & \multirow{3}{*}{ Enzyme concentration $(\mu \mathrm{L})$} & \multicolumn{5}{|c|}{ Screening method } \\
\hline & & \multicolumn{4}{|c|}{ Diameter of zones (mm) } & \multirow[b]{2}{*}{ Clot lysis \% } \\
\hline & & Blood agar plate & Heated plasma agar plate & Caseinolytic agar plate & Skim milk agar plate & \\
\hline \multirow{3}{*}{ ASIA1 } & 10 & 0.80 & 1.00 & 0.20 & 0.40 & 10 \\
\hline & 20 & 1.20 & 1.20 & 0.50 & 0.60 & 23 \\
\hline & 30 & 1.50 & 1.40 & 0.90 & 0.80 & 50 \\
\hline \multirow{3}{*}{ ASIA2 } & 10 & 1.00 & 0.80 & 0.40 & 0.20 & 28 \\
\hline & 20 & 1.60 & 1.30 & 0.80 & 0.60 & 42 \\
\hline & 30 & 1.90 & 1.60 & 1.10 & 0.90 & 65 \\
\hline \multirow{3}{*}{ ASIA3 } & 10 & 1.40 & 1.00 & 0.80 & 0.80 & 24 \\
\hline & 20 & 1.90 & 1.90 & 1.30 & 1.10 & 51 \\
\hline & 30 & 2.20 & 2.10 & 1.70 & 1.20 & 74 \\
\hline \multirow{3}{*}{ ASIA4 } & 10 & 1.80 & 2.00 & 1.30 & 0.80 & 30 \\
\hline & 20 & 2.20 & 2.80 & 1.80 & 1.50 & 69 \\
\hline & 30 & 2.60 & 3.60 & 2.50 & 2.00 & 86 \\
\hline \multirow{3}{*}{ ASIA5 } & 10 & 1.10 & 0.90 & 0.60 & 0.30 & 19 \\
\hline & 20 & 1.70 & 1.30 & 1.10 & 0.70 & 40 \\
\hline & 30 & 2.00 & 1.90 & 1.40 & 1.00 & 67 \\
\hline \multirow{3}{*}{ ASIA6 } & 10 & 0.90 & 1.00 & 0.30 & 0.20 & 11 \\
\hline & 20 & 1.20 & 1.50 & 0.80 & 0.50 & 30 \\
\hline & 30 & 1.50 & 1.78 & 1.40 & 0.90 & 59 \\
\hline
\end{tabular}

Table 2: Evaluation the productivity of staphylokinase in S. aureus isolates using different fermentation media.

\begin{tabular}{|c|c|c|}
\hline \multirow{2}{*}{ Producing strain } & \multicolumn{2}{|c|}{ Enzyme productivity (U/mL) } \\
\hline & Tryptic soy broth medium (TSB) & Casein hydrolysate yeast extract broth medium (CHYB) \\
\hline S. aureus ASIA1 & 2.10 & 2.20 \\
\hline S. aureus ASIA2 & 1.88 & 2.93 \\
\hline S. aureus ASIA3 & 4.83 & 1.95 \\
\hline S. aureus ASIA4 & 5.98 & 2.08 \\
\hline S. aureus ASIA5 & 3.41 & 3.65 \\
\hline S. aureus ASIA6 & 2.08 & 1.70 \\
\hline
\end{tabular}

hydrolyzed casein and produce radial caseinolysis zone ranged from 6 to $25 \mathrm{~mm}$ [4].

Quantitative evaluation of staphylokinase activity in clinical S. aureus strains using different fermentation media

Each S. aureus isolate was inoculated into two different fermentation media, tryptone soy broth and casein hydrolysate yeast extract broth, incubated for $24 \mathrm{~h}$ at $37^{\circ} \mathrm{C}$, after fermentation period, fermented media were centrifuged at $10,000 \mathrm{rpm}$ and the free cells supernatants were collected for detection of staphylokinase enzyme $(\mathrm{U} / \mathrm{mL})$. Results in table 2 indicated that the impact of tryptone soy broth medium and casein hydrolysate yeast extract (CYEB) on staphylokinase production was dependent on the producing strain. Tryptone soy broth supported the highest staphylokinase production in $S$. aureus ASIA3, ASIA4 and ASIA6 which estimated to be 4.83, 5.98 and $2.08 \mathrm{U} /$ $\mathrm{mL}$ but these yields were reduced to $1.95,2.08$ and $1.70 \mathrm{U} /$ $\mathrm{mL}$, respectively on casein hydrolysate yeast extract broth. Conversely, CYEB medium was the best production medium for staphylokinase from $S$ a areus ASIA1, ASIA2 and ASIA5 which gave 2.20, 2.93 and $3.65 \mathrm{U} / \mathrm{mL}$ compared to 2.10, 1.88 and $3.41 \mathrm{U} / \mathrm{mL}$ on TSB (Table 2). Then, S. aureus ASIA4 $(5.98 \mathrm{U} / \mathrm{mL})$ was chosen as the hyperactive staphylokinase producer for optimization and characterization studies on TSB medium. In line with our results Devriese and Kerckhovea, reported that tryptone soya medium was promising medium for more than $91 \%$ of 55 S. aureus strains of human origin compared to $18 \%$ with nutrient agar for staphylokinase productivity [13].

\section{Optimization the production process parameters of staphylokinase by S. aureus ASIA4}

The influence of $\mathrm{pH}$ of medium on staphylokinase production by $S$. aureus ASIA4 was performed at varied $\mathrm{pH}$ values; the enzyme productivity was increased by increasing the $\mathrm{pH}$ value from 4.0 to 7.0 and then decreased (Table 3 ). The enzyme yields were increased by 1.44-, 2.89-, 5.93-, 3.48- and 2.14-fold after increasing the $\mathrm{pH}$ of medium from 4.0 to 5.0, $6.0,7.0,8.0$ and 9.0, respectively, then $\mathrm{pH} 7.0$ was the optimal $\mathrm{pH}$ for $S$ aureus ASIA4 staphylokinase production (Table 3). In accordance with the present work Kotra, et al. reported that pH 7.0 is the best for maximizing growth and enzyme productivity and then decrease at lower or higher pHs [26]. Furthermore, $S$. aureus ASIA4 was able to grow and produce staphylokinase at a wide range of temperature, it produced $3.38,4.95,8.91$ and $7.98 \mathrm{U} / \mathrm{mL}$ at incubation temperature of $25,30,35$ and $37^{\circ} \mathrm{C}$, respectively and then sharply decreased to $4.13 \mathrm{U} / \mathrm{mL}$ at $40{ }^{\circ} \mathrm{C}$, hence optimum temperature was $35^{\circ} \mathrm{C}$ (Table 3). Deepa et al., reported that variation of $\mathrm{pHs}$ and incubation temperatures had a large impact on the uptake of the nutrients by the cells; hence, this phenomenon makes it mandatory to optimize the $\mathrm{pH}$ of the medium and incubation temperature [4]. Staphylokinase (SAK) production by Staphylococcus sp. was greatly affected at highly acidic and alkaline $\mathrm{pH}$ but the maximum SAK activity was observed at pH 6.5 at $30{ }^{\circ} \mathrm{C}$ and decrease with further increase in the incubation temperature [4]. 
Different sugars including glucose, starch, sucrose, sorbitol and lactose were evaluated as sole carbon source for staphylokinase production. The best yield of enzyme production $(10.85 \mathrm{U} / \mathrm{mL})$ from $S$. aureus ASIA4 was achieved with sucrose followed by Maltose $(9.70 \mathrm{U} / \mathrm{mL})$ while the lowest yield of enzyme was obtained with lactose, sorbitol and starch (5.35, 2.43 and $4.90 \mathrm{U} / \mathrm{mL}$, respectively) as sole carbon source compared to $8.91 \mathrm{U} / \mathrm{mL}$ with glucose (control, Table 4). Kotra, et al. reported that amongst diverse sugars such as fructose, galactose, lactose, maltose, glucose and sucrose; only glucose supported the maximum productivity of staphylokinase [26].

Moreover, basal nitrogen source of TSB medium (3.0 g soya bean $+10.0 \mathrm{~g}$ pancreatic digest of casein) by the organic nitrogen sources comprise beef extract, casein, peptone,

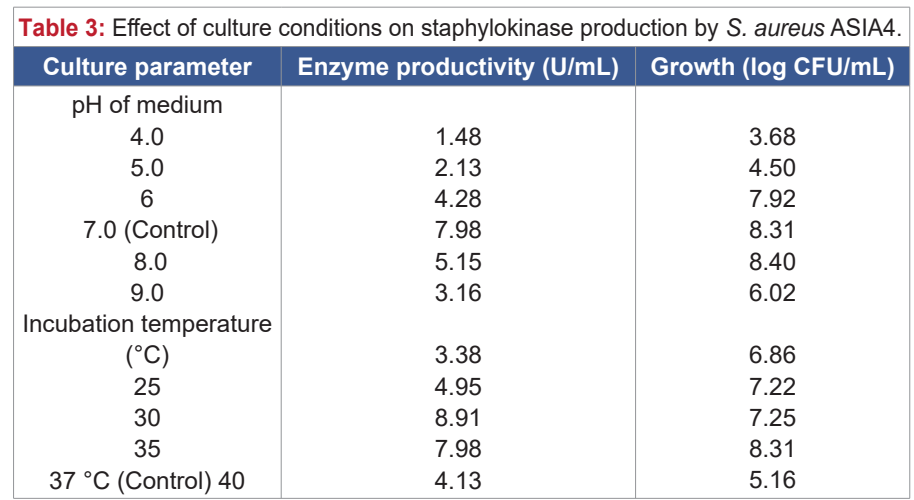

Table 4: Optimization of nutritional requirements for staphylokinase production by S. aureus ASIA4.

\begin{tabular}{|c|c|c|}
\hline Culture parameter & $\begin{array}{l}\text { Enzyme productivity } \\
\text { (U/mL) }\end{array}$ & $\begin{array}{c}\text { Growth (log CFU/ } \\
\mathrm{mL})\end{array}$ \\
\hline Sole carbon source $(5 \mathrm{~g} / \mathrm{L})$ & & \\
\hline Glucose (Control) & 8.91 & \\
\hline Fructose & 8.24 & 7.82 \\
\hline Starch & 4.90 & 7.90 \\
\hline Maltose & 9.70 & 5.16 \\
\hline Sucrose & 10.85 & 6.54 \\
\hline Sorbitol & 2.43 & 7.31 \\
\hline Lactose & 5.35 & 3.48 \\
\hline Sole nitrogen source (10 g/L) & & 4.85 \\
\hline (Control) & 10.80 & \\
\hline Soy bean & 15.79 & 8.10 \\
\hline Casein & 12.63 & 6.01 \\
\hline Peptone & 11.16 & 8.83 \\
\hline Beef extract & 6.59 & 8.14 \\
\hline Yeast extract & 14.22 & 8.90 \\
\hline Corn steep liquor & 5.10 & 8.00 \\
\hline $\mathrm{NH}_{4} \mathrm{NO}_{3}$ & 11.02 & 6.15 \\
\hline $\begin{array}{l}\text { Amino acid supplementations } \\
\qquad(2 \mathrm{~g} / \mathrm{L})\end{array}$ & & 4.73 \\
\hline Control & 15.88 & 6.10 \\
\hline Alanine & 3.73 & 10.15 \\
\hline Glycine & 2.00 & 11.93 \\
\hline Histidine & 3.90 & 10.00 \\
\hline Lysine & 4.73 & 11.19 \\
\hline $\begin{array}{c}\text { Minerals supplementation (5 } \\
\mathrm{g} / \mathrm{L})\end{array}$ & & \\
\hline Control (NaCl) & 15.88 & 4.90 \\
\hline $\mathrm{CaCl}_{2}$ & 2.83 & 5. 08 \\
\hline $\mathrm{MgCl}_{2}^{2}$ & 8.25 & 3.86 \\
\hline $\mathrm{FeSO}_{4}$ & 4.37 & 2.91 \\
\hline $\mathrm{KNO}_{3}$ & 8.00 & 8.77 \\
\hline $\mathrm{ZnSO}_{4}$ & 7.29 & 7.14 \\
\hline $\mathrm{CuSO}_{4}$ & 4.75 & 3.70 \\
\hline
\end{tabular}

corn steep liquor and yeast extract, individually the enzyme productivity increased from 10.80 to $11.16,12.63,14.22$ and $15.79 \mathrm{U} / \mathrm{mL}$ with the organic nitrogen sources peptone, casein, yeast extract and soy bean, respectively while the inorganic nitrogen $\mathrm{NH}_{4} \mathrm{NO}_{3}$ increased staphylokinase productivity to $11.02 \mathrm{U} / \mathrm{mL}$ (Table 4). On the other hand the productivity was decreased by $38.98 \%$ and $52.77 \%$ with beef extract and corn step liquor, respectively, then soy bean was the best nitrogen source (Table 4).

Moreover, all amino acids supplementations include alanine, glycine, histidine and lysine had negative effects on staphlokinase production. They decreased enzyme production by $76.21 \%, 87.25 \%, 75.13 \%$ and $69.83 \%$, respectively but they increased the growth by $66.39 \%, 95.97 \%, 62.93 \%$ and $83.44 \%$ (Table 4); which may be due to the imbalance in the $\mathrm{C} / \mathrm{N}$ ratio occurred after adding each of these amino acids to the soy bean as well as the lower productivity of the enzyme can be attributed to the fact that the amino acids encouraged and prolonged the growth phase at the expense of the production phase as previously stated [27]. Kotra, et al. suggested yeast extract as the best nitrogen to achieve the highest yield of growth and staphylokinase enzyme [26]. Also Deepa, et al. suggested that yeast extract acts as a major nitrogen source for the production of SAK and shows maximum activity at a concentration of $2.65 \%(\mathrm{w} / \mathrm{v})$ [4].

In the case of replacing the basic medium salt sodium chloride by $\mathrm{CaCl}_{2}, \mathrm{MgCl}_{2}, \mathrm{FeSO}_{4}, \mathrm{KNO}_{3}, \mathrm{ZnSO}_{4}$ and $\mathrm{CuSO}_{4}$ separately, the enzyme productivity is significantly reduced from $15.88 \mathrm{U} / \mathrm{mL}$ to $2.83,8.25,4.37,8.00,7.29$ and 4.75 $\mathrm{U} / \mathrm{mL}$, respectively (Table 4). The optimized process parameters for maximum staphylokinase production by $S$. aureus ASIA4 were TSB as production medium containing sucrose as carbon source at $5 \mathrm{~g} / \mathrm{L}$, soya bean as nitrogen source at $10 \mathrm{~g} / \mathrm{L}, \mathrm{NaCl}$ at $5 \mathrm{~g} / \mathrm{L}, \mathrm{K}_{2} \mathrm{HPO}_{4} 2.5 \mathrm{~g}$, pH $7.0 \pm 0.2$ and incubation for $24 \mathrm{~h}$ at temperature $35^{\circ} \mathrm{C}$ that increased staphylokinase productivity from $2.08 \mathrm{U} / \mathrm{mL}$ on casein hydrolysate yeast extract broth medium (CYEB) to 15.88 $\mathrm{U} / \mathrm{mL}$ (7.64-fold increase). Interestingly in most cases of parameters optimized under SMF no clear correlation was observed between the biomass yield and staphylokinase production. the highest microbial growth 7.90 and $7.82 \mathrm{log}$ $\mathrm{CFU} / \mathrm{mL}$ recorded with fructose and glucose as well as 8.00 and $8.90 \log \mathrm{CFU} / \mathrm{mL}$ obtained with beef extract and yeast extract but growth values markedly increased with adding amino acid alanine, glycine, histidine and lysine to reach 10.15, 11.93, 10.00 and $11.19 \log \mathrm{CFU} / \mathrm{mL}$, respectively. Consistent with literature sources, the optimum temperature for the growth of $S$. aureus was ranged from 37 to $40{ }^{\circ} \mathrm{C}$ as well as beef extract, dextrose and $\mathrm{NaCl}$ were reported as the most suitable parameters [18,23,24].

\section{Characterization of staphylokinase enzyme}

Temperature and $\mathrm{pH}$ of enzymatic reaction among the 
most important factors that impacted both enzyme activity and stability, the enzyme retained $100 \%$ of its activity at temperature ranged between 15 to $45{ }^{\circ} \mathrm{C}$ and then lost $40 \%$, $56 \%$ and $81 \%$ of its activity at 50,55 and $60{ }^{\circ} \mathrm{C}$, respectively but the maximum enzyme activity was achieved at $40{ }^{\circ} \mathrm{C}$ (Figure6). Nguyen andQuyenreported that thestaphylokinase from $S$. aureus QT08 was active in a broad temperature range of 20 to $45^{\circ} \mathrm{C}$ and had optimum temperature of 30 to $37^{\circ} \mathrm{C}$ along with it was stable at a temperature range from 15 to $37^{\circ} \mathrm{C}$ but it was inactive at high temperature $\left(70^{\circ} \mathrm{C}\right)[28,29]$.

Activity of staphylokinase compared to the control (pH 7.0 with $100 \%$ relative activity) was significantly affected at the acidic $\mathrm{pH}$ and lost $68.4 \%$ of its activity at $\mathrm{pH} 5.0$ but it was slightly affected at alkaline $\mathrm{pH}$ and lost $4.8 \%$ of its relative activity at pH 9.0. The staphylokinase activity reached its beak at pH 8.0. However, the enzyme was stable and retained $100 \%$ of its activity at pH ranged between pH 6.0 to pH 9.0 (Figure 7). Interestingly, Nguyen and Quyen recommended pH 8.5 in Tris-HCl buffer and pH 7.5 in phosphate buffer for the best SAK activity with $\mathrm{pH}$ stability at a pH range of 4.0 to 9.0 [28].

The optimum reaction time for staphylokinase enzyme with casein as substrate was estimated to be $25 \mathrm{~min}$ but at lower reaction time the enzyme activity was loosed $74.8 \%, 67.6 \%, 44.20 \%$ and $20.20 \%$ after reaction time equal to 5, 10, 15 and $20 \mathrm{~min}$ (Figure 8) as well as among varied concentrations ranged between 0.45 to $3.6 \mathrm{mM}$; $0.45,0.90$ and $1.80 \mathrm{mM}$ increased the enzymatic activity by $6 \%, 15 \%$ and $7 \%$, respectively and then decreased at higher concentrations of casein (Figure 9). Our results are in agreement with Chandrappa, et al. they reported that the optimum enzymatic reaction time for staphylokinase from Staphylococcus was 20 to $30 \mathrm{~min}$ [7].

In addition, data in figure 10 showed the effect of different concentrations from $\mathrm{MgCl}_{2}, \mathrm{NaCl}$ and EDTA ranged from 10 to $90 \mathrm{mM}$, individually on staphylokinase activity. EDTA inhibited the enzyme activity by $3 \%$ to $32.2 \%$ with increasing its values from 30 to $90 \mathrm{mM}$; $\mathrm{MgCl}_{2}$ at a concentration of 30 $\mathrm{mM}$ increased the enzyme activity by $4 \%$ and then slightly decreased at higher concentrations up to $90 \mathrm{mM}$ but $\mathrm{NaCl}$ was potent staphylokinase activator at concentrations lower than $90 \mathrm{mM}$ which decrees its activity by $4.87 \%$ (Figure 10). In coincident with our results Nguyen and Quyen revealed that the addition of metal ions $\mathrm{Cu}^{2+}, \mathrm{Fe}^{3+}, \mathrm{Co}^{2+}$ and $\mathrm{Zn}^{2+}$ as well as EDTA at the lower concentration showed no or slightly inhibitory effect on enzyme activity whereas the addition of metal ions and EDTA at the higher concentration of than $25 \mathrm{mM}$ significantly inhibited the enzyme. However, Yarzábal et al., stated that in almost all cases, a decrease of the initial velocity of activation was observed with EDTA and a wide range of metal ions [30]. These results supported microorganisms as a prolific resource for pharmaceutical agents as recently reported by many authors [31,32].

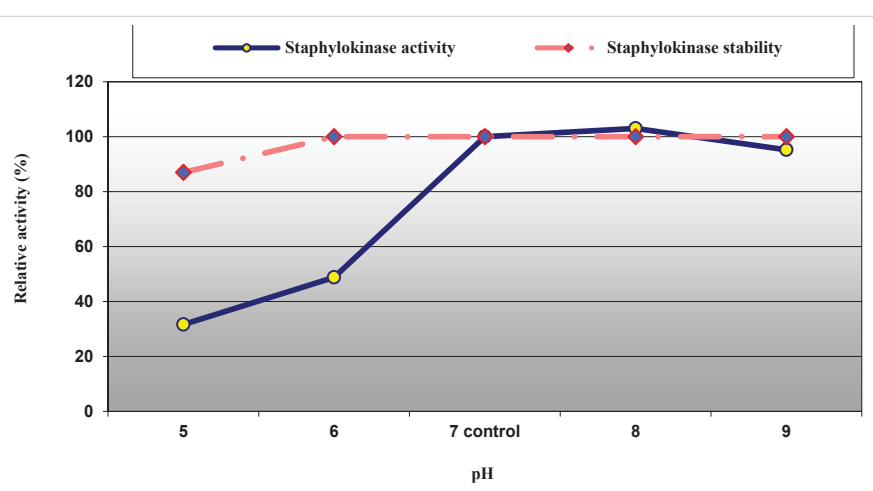

Figure 7: Effect of pH on staphylokinase activity and stability from S. aureus ASIA4.

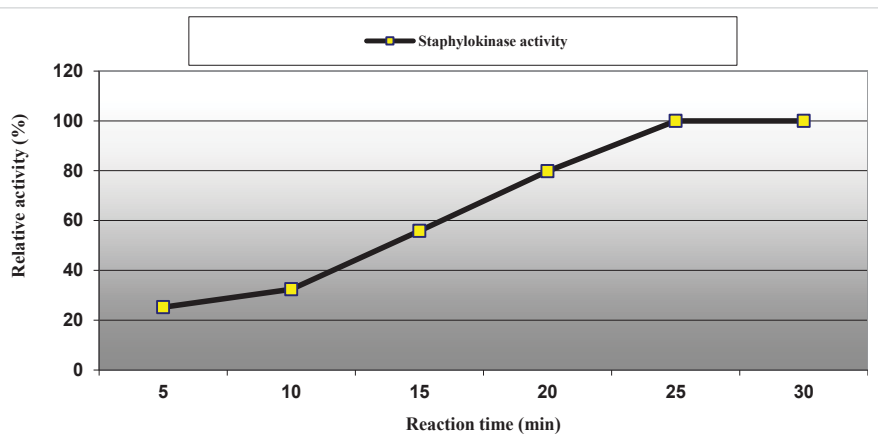

Figure 8: Effect of reaction times on staphylokinase activity produced from $\mathrm{S}$. aureus ASIA4.

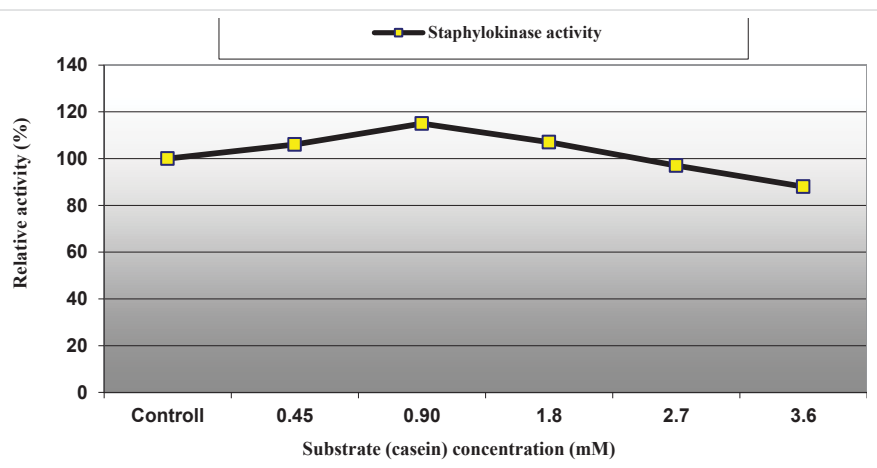

Figure 9: Effect of substrate (casein) concentration on staphylokinase activity produced from S. aureus ASIA4.

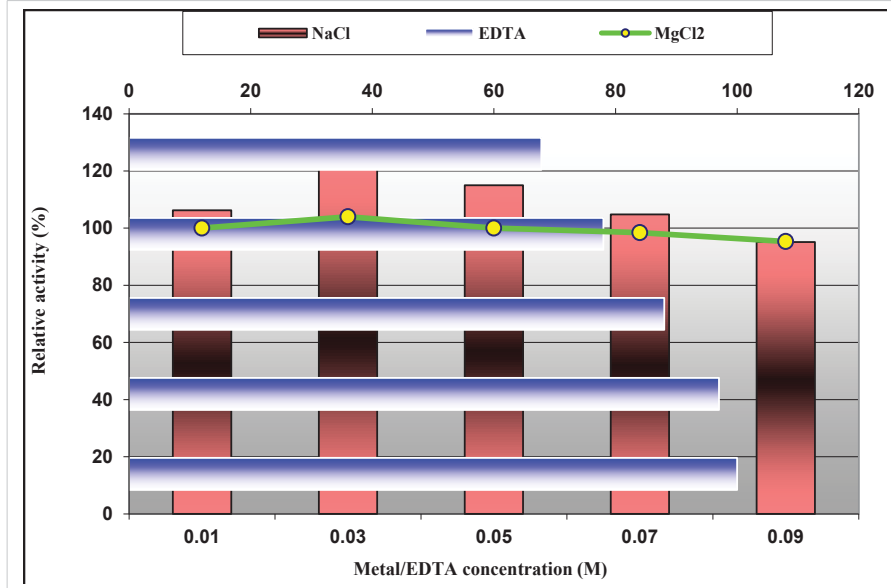

Figure 10: Effect of different concentrations from $\mathrm{MgCl}_{2}, \mathrm{NaCl}$ and EDTA on staphylokinase activity produced from S. aureus ASIA4. 


\section{Conclusion}

Myocardial infarction has increased dramatically in current years resulting in heart attacks and strokes. The focus of this study is on the enzyme staphylokinase which is a potent thrombolytic agent produced from $S$. aureus with the aim of increasing the production and reducing the cost compared to existing thromobolytic agents. All six $S$. aureus that normally found in human (isolated from urinary tract infection, burn abuses infection and cancer of bone marrow) were positive to coagulase, mannitol fermentation, casein and blood hydrolysis ( $\beta$-haemolysis) tests along with significant staphylokinase, SAK, productivity. Strain S. aureus ASIA4 was the hyper SAK producer. With regard to the production point of view, the fermentation process parameters were optimized through improving medium ingredients and other individual physicochemical parameters get the maximum enzyme productivity from the hyper producer strain S. aureus ASIA4. The assay parameters optimization and characterization of staphylokinase enzyme were done here in this study. The final yield was remarkably increased by 7.64-fold after optimization processes. The study revealed that the selected isolate ASIA4 could be a promising staphylokinase producer and hence could be used efficiently in the future for the inexpensive and effective production of thrombolytic drugs.

\section{References}

1. Min W, Yao C, Wenliang F, Minji Z, Yuanyuan W, et al. Construction of a novel staphylokinase (SAK) mutant with low immunogenicity and its evaluation in rhesus monkey. Int J Biol Macromol. 2020; 146: 781-789. PubMed: https://pubmed.ncbi.nlm.nih.gov/31730959/

2. Nedaeinia R, Faraji $\mathrm{H}$, Javanmard $\mathrm{SH}$, et al. Bacterial staphylokinase as a promising third-generation drug in the treatment for vascular occlusion. Mol Biol Rep. 2020; 47: 819-841.

PubMed: https://pubmed.ncbi.nlm.nih.gov/31677034/

3. Shah NR, Panchal HK. Screening of staphylokinase producing Staphylococcus spp. from different sources. GJBB. 2019; 8: 194-197.

4. Deepa K, Faujdar SS, Azmi W, Mehrishi P, Solanki S. Screening and optimization of staphylokinase from Staphylococcus aureus isolated from nasal swab of healthy students in Himachal Pradesh University, India. Biomed Biotechnol Res J. 2019; 3: 228-232.

5. Jasim HM, Dellol RA, Hamzah AS. Optimum conditions of staphylokinase production cloned in E. coli Jm109 (De3). Int J Curr Microbiol Appl Sci. 2015; 4: 10-19.

6. Faraji $\mathrm{H}$, Soltani $\mathrm{F}$, Ramezani $\mathrm{M}$, et al. Designing a multifunctional staphylokinase variant (SAK-2RGD-TTI) with appropriate thrombolytic activity in vitro. Biotechnol Lett. 2020; 42: 103-114.

PubMed: https://pubmed.ncbi.nlm.nih.gov/31686286

7. Chandrappa CP, Singh M, Chandrasekar N, Govindappa M. Production and partial purification of staphylokinase from Staphylococcus hominis. Res J Pharmaceut Biological Chem Sci. 2017; 8: 77-86.

8. Lemaire S. Intracellular Staphylococcus aureus, an emerging links to persistent and relapsing infections: factors influencing the activity of antimicrobials against intracellular S. aureus. Doctoral Thesis, Université Catholique de Louvain. 2008; 14: 766-777.

9. Atlas M, Parks C, Brown A. Laboratory manual of experimental microbiology. Mosby-Year-Book, Inc., 1995; USA.

10. Collee J, Miles R, Watt B. Tests for the identification of bacteria.
In: Practical medical microbiology. Collee J, Fraser A, Marmion B, Simmons A. (eds.), 4th edition, 1996; Churchill Livingstone, U.K.

11. Harly J, Prescott L. Laboratory exercises microbiology. 5th Ed, WCB, 2002; The Mcgraw-Hill Companies. New York.

12. Kateete DP, Kimani CN, Katabazi FA, Okeng A, Okee MS, et al. Identification of Staphylococcus aureus: DNase and mannitol salt agar improve the efficiency of the tube coagulase test. Ann Clin Microbiol Antimicrob. 2010; 9: 23.

13. Devriese LA, Kerckhovea AV. Comparison of methods used for testing staphylokinase (fibrinolysin) production in Staphylococcus strains. Antonie van Leeuwenhoek. 1980; 46: 457-465. PubMed: https://pubmed.ncbi.nlm.nih.gov/6453557/

14. Kondo I, Fujise K. Serotype B staphylococcal bacteriophage singly converting staphylokinase. Infect Immun. 1977; 18: 266-272. PubMed: https://www.ncbi.nlm.nih.gov/pmc/articles/PMC7163009/

15. Pulicherla KK, Gadupudi GS, Rekha VP, Seetharam B, Rao K. International Journal of Advanced Science and Technology. 2011; 30.

16. Shagufta NB, Ravi M, Subhashchandra MG, Jayaraj YM. Screening of staphylokinase producing Staphylococcus aureus from clinical samples. Int J Res Biological Sci. 2014; 4: 46-48.

17. Devi S, Mohanasrinivasan V, Vaishnavi B, Selvarajan E, Naine SJ. Optimization studies for enhanced production of streptokinase by Streptococcus equisimilis UVM6 C. J Pure Appl Microbiol. 2013; 7: 1-5.

18. Medved'ová A, Valík L', Sirotná Z, Czech DL. Growth characterization of Staphylococcus aureus in milk: a quantitative approach. Food Sci. 2009; 27: 443-453.

19. Sutherland JP, Bayliss AJ, Roberts TA. Predictive modelling of growth of Staphylococcus aureus: the effects of temperature, $\mathrm{pH}$ and sodium chloride. Int J Food Microbiol. 1994; 21: 217-236. PubMed: https://pubmed.ncbi.nlm.nih.gov/8024974/

20. Singh D, Chand AE, Goel S. Prevalence of MRSA among Staphylococcus aureus isolated from patients of urinary tract infection along with its antibiogram. Int J Med Sci Current Res. 2019; 2: 364-370.

21. Abdulzahra AA, Al-Jameel R, Akool MA-Z, Al-Jameel DS. Prevalence of toxic shock syndrome toxin-1 (TSST-1) produced by Staphylococcus aureus isolated from patient combined psoriasis with urinary tract infections (UTIs) and gastroenteritis in age groups between 8-18 years. Sys Rev Pharm. 2020; 11: 80-85.

22. El-Gendy MMA, Abdel-Wahhab KG, Mannaa FA, Farghaly AA, ElBondkly AMA. Carcinogenic activities and sperm abnormalities of methicillin resistance Staphylococcus aureus and inhibition of their virulence potentials by ayamycin. Applied biochemistry and biotechnology. 2017; 183: 833-852.

PubMed: https://pubmed.ncbi.nlm.nih.gov/28389766/

23. El-Gendy MMAA, El-Bondkly AMA, Keera AA, Ali AM. Incidence of methicillin-resistant Staphylococcus aureus (MRSA) in microbial community of cancer patients and evaluation of their resistant pattern. Arabian J Sci Engineering. 2018a; 43: 83-92.

24. El-Gendy MMA, Mohamed ZK, Hekal NZ, Ali FM, Yousef AEM. Production of bioactive metabolites from different marine endophytic Streptomyces species and testing them against methicillin-resistant Staphylococcus aureus (MRSA) and cancer cell lines. BioTechnologia. 2018b; 99: 13-35.

25. Morello JK, Mizer HE, Granato PA. Laboratory manual and work book in microbiology applications to patient care. 2006; 8thed. Mc Graw Hill.

26. Kotra SR, Kumar A, Rao S, Pulicherla KK. Statistical optimization of media components for enhanced production of the recombinant staphylokinase variant from salt inducible E.Coli GJ1158. Int J Bio-Sci Bio-Technol. 2012; 4: 27-40.

27. El-Bondkly AAM, El-Gendy MMAA, El-Bondkly EAM, El-Bondkly AAM. Biodiversity and biological activity of the fungal microbiota 
derived from the medicinal plants Salvia aegyptiaca L. and Balanties aegyptiaca L. Biocataly Agricult Biotechnology. 2020; 28: 101720.

28. Nguyen THT, Quyen DT. High-level expression, purification and properties of a fully active even glycosylated staphylokinase variant Sak $\varphi$ C from Staphylococcus aureus QT08 in Pichia. African J Microbiol Res. 2012; 6: 2129-2136.

29. Schlott B, Hartmann M, Gührs K, et al. High yield production and purification of recombinant staphylokinase for thrombolytic therapy. Nat Biotechnol. 1994; 12: 185-189.

PubMed: https://pubmed.ncbi.nlm.nih.gov/7764434/
30. Yarzábal LA. Modulation of staphylokinase-dependent plasminogen activation by mono- and divalent ions. Brazi J Med Biological Res. 1999; 32: 39-43.

31. El-Bondkly AAM, El-Gendy MMAA, El-Bondkly AMA. Construction of efficient recombinant strain through genome shuffling in marine endophytic Fusarium sp. ALAA-20 for improvement lovastatin production using agro-industrial wastes. Arab J Sci Eng. 2020.

32. El-Bondkly AAM, El-Gendy MMAA, El-Bondkly EAM, Ahmed AM. Biodiversity and biological activity of the fungal microbiota derived from the medicinal plants Salvia aegyptiaca L. and Balanties aegyptiaca L. Biocatalysis and Agricultural Biotechnology. 2020; 28: 101720. 